\title{
The INMA-INfancia y Medio Ambiente-(Environment and Childhood) Project: more than 10 years contributing to environmental and neuropsychological research
}

Mireia Gascon ${ }^{1,2,3}$, Mònica Guxens ${ }^{1,2,3,4}$, Martine Vrijheid ${ }^{1,2,3}$, Maties Torrent ${ }^{5}$, Jesús Ibarluzea $3,7,8,9$, Eduardo Fano ${ }^{8,9}$, Sabrina Llop ${ }^{3,10}$, Ferran Ballester ${ }^{3,10}$, Mariana F. Fernández ${ }^{3,11}$, Adonina Tardón ${ }^{3,12}$, Ana Fernández-Somoano ${ }^{3,12}$, Jordi Sunyer ${ }^{1,2,3,13}$

\section{Affiliations}

${ }^{1}$ ISGlobal, Centre for Research in Environmental Epidemiology (CREAL), Barcelona, Spain

${ }^{2}$ Universitat Pompeu Fabra (UPF), Barcelona, Spain

${ }^{3}$ CIBER Epidemiología y Salud Pública (CIBERESP), Spain

${ }^{4}$ Department of Child and Adolescent Psychiatry/Psychology, Erasmus University

Medical Centre-Sophia Children’s Hospital, Rotterdam, The Netherlands

${ }^{5}$ Àrea de Salut de Menorca, IB-SALUT, Menorca, Spain

${ }^{7}$ Subdirección de Salud Pública de Gipuzkoa, The Basque Government's Health Department, San Sebastián, Spain

${ }^{8}$ Faculty of Psychology, University of the Basque Country UPV/EHU, Donostia, Spain ${ }^{9}$ BIODONOSTIA, Health Research Institute, San Sebastián, Basque Country, Spain ${ }^{10}$ Epidemiology and Environmental Health Joint Research Unit, FISABIO-Universitat Jaume I-Universitat de València, València, Spain

${ }^{11}$ University of Granada, Complejo Hospitalario Universitario, Instituto de Investigación Biosanitaria (ibs.GRANADA), Granada, Spain 
${ }^{12}$ Área de Medicina Preventiva y Salud Pública, Departamento de Medicina, Universidad de Oviedo, Asturias, Spain

${ }^{13}$ IMIM (Hospital del Mar Medical Research Institute), Barcelona, Catalonia, Spain

\section{Corresponding author}

Mireia Gascon Merlos

Parc de Recerca Biomèdica de Barcelona (PRBB)

Doctor Aiguader, 88 | 08003 Barcelona, Catalonia, Spain

Phone: $0034932147353 \quad$ Fax: 0034932045904

email: mireia.gascon@isglobal.org 


\section{Abstract}

Background: In 2003 the INMA-INfancia y Medio Ambiente (Environment and Childhood) Project, a Spanish national network of birth cohorts including more than 3500 participants, was set up with the aim to assess the health impacts of pre- and postnatal environmental exposures on children. The project has published more than 60 papers on maternal and environmental factors related to neuropsychological development in children, one of the main research interests within the project. With the present review, we evaluate the evidence provided by the INMA project on this topic and discuss how the data can contribute to cover the challenges that children's environmental health research will face in the coming years.

Results: the INMA project has contributed to provide increasing evidence of the association between prenatal exposure to persistent organic pollutants (POPs) and child neuropsychological development, but it has also shown, using innovative methodologies, that postnatal exposure to these compounds does not play a role in this association. The project has also contributed to show the detrimental influence of certain air pollutants on child neuropsychological development, as well as how a balanced maternal fish intake can protect from the potential adverse effects of prenatal exposure to mercury. Also, the project has contributed to the understanding of impacts of nutritional factors including supplement intake and vitamin D levels during pregnancy and the role of breastfeeding on the neuropsychological benefits.

Conclusions: INMA findings underscore the importance of continued research on the delineation of the sensitive windows of exposure both during pregnancy and postnatally and on the combined effects of environmental exposures, denoted the exposome. In terms of health policy, INMA findings have important implications for the development of public health policies to advance the health and development of children. 
Keywords: neuropsychological development; environmental epidemiology; pollutants;

prenatal; postnatal; INMA project

\section{Abbreviations}

\begin{tabular}{|c|c|}
\hline ADHD & attention-deficit hyperactivity disorder \\
\hline ADHD-DSM-IV & $\begin{array}{l}\text { criteria of the diagnostic and statistical manual of mental } \\
\text { disorders } 4^{\text {th }} \text { edition }\end{array}$ \\
\hline BPA & bisphenol A \\
\hline BSID-I & Bayley scales of infant development $1^{\text {st }}$ edition \\
\hline CAST & childhood Asperger syndrome test \\
\hline CBCL/6-18 & child behavior checklist \\
\hline CI & confidence interval \\
\hline CPSCS & California preschool social competence scale \\
\hline CSRS & Conner's' parent rating scales \\
\hline DDE & dichlorodiphenyldichloroethylene \\
\hline DDT & dichlorodiphenyltrichloroethane \\
\hline DEHPs & di-(2-ethylhexyl) phthalate \\
\hline GSID & Griffiths scales of infant development \\
\hline HCB & hexachlorobenzene \\
\hline INMA & infancia y medioambiente (environment and childood) \\
\hline IRR & incidence rate ratio \\
\hline MBzP & mono-benzyl phthalate \\
\hline MDI & mental development index \\
\hline MCSA & McCarthy scales of children's abilities \\
\hline $\mathrm{NO}_{2}, \mathrm{NO}_{\mathrm{x}}$ & nitrogen dioxide \\
\hline OR & odds ratio \\
\hline PBDE47 & polybrominated diphenyl ethers \\
\hline PCBs & polychlorinated biphenyls \\
\hline PDI & psychomotor developmental index \\
\hline $\mathrm{PM}_{2.5}, \mathrm{PM}_{10}, \mathrm{PM}$ & eparticulate matter $(2.5,10$, coarse $)$ \\
\hline POPs & persistent organic pollutants \\
\hline RR & relative risk \\
\hline SDQ & strengths and difficulties questionnaire \\
\hline SE & standard error \\
\hline TSH & thyroid-stimulating hormone \\
\hline
\end{tabular}




\section{Introduction}

In 2003 the INMA-Infancia y MedioAmbiente (Environmental and Childhood) project, a Spanish national network of birth cohorts aimed at assess the health impacts of pre- and postnatal environmental exposures on children, was set up ${ }^{1}$. The first cohorts started in 1997 in the locations of Ribera d'Ebre (n=102) and Menorca (n=482), in 2001 another birth cohort was set up Granada ( $n=668$, including only boys). Based on the experience from these three cohorts, a new common research protocol was developed and four new cohorts were designed to evaluate the impact of environmental exposures and diet on children's health: Valencia ( $n=787)$, Sabadell $(n=622)$, Asturias $(n=485)$ and Gipuzkoa $(n=612)^{2,3}$. Overall, the project includes more than 3500 participant motherchild pairs.

Since 2001, the number of original papers published by the project has exponentially increased and so far more than 300 articles are contributing to the knowledge of the association between pre- and postnatal environmental exposures and child health. One of the main research interests within the INMA project has been the study of the neuropsychological development of children and, along the years, different tools, listed in Table 1, have been used in order to evaluate cognitive and psychomotor functions as well as behavioral outcomes.

Overall, the INMA project has published more than 60 papers on maternal and environmental factors related to neuropsychological development in children. Beyond the work conducted by other research teams, that contributes to the evidence of the associations between environmental factors and neuropsychological development in children, and beyond the mechanisms that explain these associations, which have been 
discussed in other articles ${ }^{4}$, with the present review we aim to evaluate the evidence provided by the INMA project up to January 2016 on which maternal and environmental determinants during pre- and postnatal life are associated with child's neuropsychological development and to discuss how INMA data is contributing to cover the challenges that child health environmental research will face in the coming years.

\section{Results}

\section{Tools to assess neuropsychological development in INMA}

General cognition was evaluated with the Bayley Scales of Infant Development $1^{\text {st }}$ edition (BSID-I) ${ }^{5}$ and the Griffiths Scales of Infant Development (GSID) ${ }^{6}$ - first two years of life - and the McCarthy Scales of Children’s Abilities (MCSA) ${ }^{7}-4$ to 5 years of life. BSID yields two indices, the Mental Development Index (MDI) and the Psychomotor Developmental Index (PDI), whereas the GSID is divided into five subscales (locomotor, personal-social, hearing and language, eye-hand coordination, and performance). MCSA provides a global score for general cognition and scores for five subscales (verbal, perceptive-performance, memory, quantitative and motor). Additionally, within the INMA project, a new summary measure was constructed to assess those cognitive tasks associated with executive functions ${ }^{8}$. At the age of 4-5 years, social competence was also evaluated with the California Preschool Social Competence Scale (CPSCS), which measures the appropriateness of preschool children's interpersonal behavior and their degree of social responsibility, and includes the concept of independence, understood as interpersonal autonomy ${ }^{9}$. Attention-deficit, hyperactivity and impulsivity, were also assessed with the Attention-Deficit Hyperactivity Disorder (ADHD) Criteria of the Diagnostic and Statistical Manual of 
Mental Disorders 4th Edition (ADHD-DSM-IV), as well as autistic traits, determined with the Childhood Asperger Syndrome Test (CAST) ${ }^{10}$. Although at the age of 7 years many tests were conducted (Table 1), so far only those related to behavioral problems the Strengths and Difficulties Questionnaire (SDQ) ${ }^{11}$, the Conners' Parent Rating Scales $(\mathrm{CPRS})^{12}$ and the Child Behavior Checklist $(\mathrm{CBCL} / 6-18)^{13}$ - have been included in publications. The SDQ, which covers common areas of emotional and behavioral difficulties, consists of 25 items that allow obtaining a global score and individual scores for five subscales (emotional symptoms, conduct problems, hyperactivity/inattention, peer relationship problems and prosocial behavior). The short form of the CPRS intends to assess problematic behavior in children and consists in summarizing the results into scores for three subscales (oppositional, cognitive problems/inattention and hyperactivity) and an ADHD index. The CBCL/6-18 provides several behavioural scales grouped by three composite scales (internalizing, externalizing and total problems scales).

\section{Prenatal and postnatal factors related to comorbidities}

\section{Prenatal determinants}

Persistent organic pollutants (POPs)

Because of their persistency and the health effects associated, the production and use of most POPs are currently banned in the majority of countries, which has led to a general reduction of the exposure levels in the environment and human tissues ${ }^{14}$. However, due to their properties, humans are still exposed to low levels of these compounds ${ }^{14}$.

In 2003 Ribas-Fitó et al. published the first paper of the INMA project about organochlorine exposure and cognitive and psychomotor development in children ${ }^{15}$. 
The study, conducted in the vicinity of an electrochemical plant in Ribera d'Ebre (Catalonia) and including 92 mother-infant pairs, observed that for each doubling of cord blood dichlorodiphenyldichloroethylene (DDE) concentration the cognitive and the psychomotor scores decreased in 3.50 points (SD: 1.39) and 4.01 points (SD: 1.37), respectively, at the age of 13 months. Later, children 4 years old from Ribera d'Ebre and Menorca $(\mathrm{N}=475)$ with dichlorodiphenyltrichloroethane (DDT) concentrations in cord serum above $0.20 \mathrm{ng} / \mathrm{ml}$ had decreased a mean of 7.86 (SE, 3.21) points in the verbal scale and 10.86 (SE, 4.33) points in the memory scale compared with those with DDT concentrations below $0.05 \mathrm{ng} / \mathrm{ml}$, with stronger associations among girls. At this age, very weak associations with DDE were observed ${ }^{16}$. Further analysis including children of the new INMA birth cohorts did not observe associations with $\operatorname{DDE}^{17}$ at the age of 1 year (Table 2).

In the first study conducted in Ribera d'Ebre, polychlorinated biphenyl (PCBs) were only marginally associated with psychomotor development at the age of 13 months ${ }^{15}$. Forns et al., in a study including 1391 children of the new INMA birth cohorts, observed that prenatal PCB exposure, and particularly to congeners 138 and 153, resulted in impairment of psychomotor $[\beta(95 \% \mathrm{CI})=-1.24,(-2.41,-0.07)]$ but not of mental development measured at around 1 year of age ${ }^{17}$. A subsequent study conducted in Menorca observed that prenatal exposure to PCB153, but not other congeners, was associated with decreased scores of all scales, except the motor scale, at the age of 4 years $^{18}$ (Table 2).

None of the studies evaluating the effects on cognitive and psychomotor development observed associations with HCB at the age of 1 year ${ }^{15,17,19}$. However, in the birth 
cohorts of Ribera d'Ebre and Menorca, children with concentrations of HCB > 1.5 $\mathrm{ng} / \mathrm{mL}$ at birth had a statistically significant increased risk of having poor social competence and ADHD scores $[(\mathrm{RR} 95 \% \mathrm{CI}=4.04$ (1.76-9.58) and 2.71 (1.05-6.96), respectively] ${ }^{19}$ (Table 2).

Prenatal exposure to mirex, measured in 104 children from Granada (only 26\% of children had detectable levels), was related with a decrease of 5.15 points in working memory and of 7.33 points in the quantitative area of the MCSA at the age of 4 years, with respect to children with prenatal mirex values below the limit of detection ${ }^{20}$ (Table 2).

In Menorca, where children were classified as exposed and non-exposed to polybrominated diphenyl ether 47 (PBDE47) according to the limit of quantification (only 45\% had detectable levels), no associations were observed between prenatal exposure and cognitive development at the age of 4 years ${ }^{21}$. However, in Sabadell and Gipuzkoa, the sum of different PBDE congeners were associated with decreasing mental development scores in the first year of life ( $\beta$ per log ng/g lipid $=-2.25$, 95\%CI 4.75, 0.26), being PBDE209 the main congener responsible for this association. No relationship with psychomotor development was observed at that age ${ }^{22}$. The association between prenatal PBDEs exposure and behavioral outcomes (ADHD symptoms and social competence) was also assessed in children from Menorca, but no associations were found ${ }^{21}$ (Table 2).

In summary, the INMA project has provided evidence of the neuropsychological impacts of prenatal exposure to some organochlorine compounds, particularly DDT/DDE and PCBs in relation to cognitive development and HCB in relation to 
behavior problems. For other POPs (mirex, PBDEs), some effects on cognitive and psychomotor development have been also described.

\section{Metals}

Certain metals are considered developmental neurotoxicants, such as methylmercury, lead, arsenic and manganese ${ }^{4}$. Medium-high prenatal exposure to mercury has been described in the INMA cohorts, with a high proportion of newborns with elevated concentrations of total mercury in cord blood ${ }^{23}$; however, these high concentrations did not associate with neither a mental $[\beta(95 \% \mathrm{CI})=0.1(-0.68,0.88)]$ or a psychomotor $[\beta$ $(95 \% \mathrm{CI})=-0.05(-0.79,0.68)]$ delay at the age of 14 months $(n=1683)^{24}$. A stratified analysis by sex suggested an impaired but not statistically significant effect on psychomotor development only in girls $[\beta(95 \% \mathrm{CI})=-1.09(-2.21,0.03)$ (interaction pvalue $=0.033$ ) $]^{24}$. In the birth cohort of Sabadell, several metals (cobalt, cupper, arsenic, cadmium, antimony and lead) were measured in urine samples of mothers during the $1^{\text {st }}$ and the $3^{\text {rd }}$ trimesters of pregnancy ${ }^{25}$. Results showed no associations between low prenatal levels of these metals and cognitive and psychomotor development or behavioral symptoms ${ }^{25}$ (Table 2). One of the limitations of this study was that the matrix and technique used to measure lead were not the most appropriate (whole blood is the most suitable biological matrix), and therefore many children were classified as having non-detectable levels ${ }^{25}$. Overall, the INMA project has shown that in this Mediterranean population, what is considered "elevated" levels of exposure to mercury during pregnancy do not seem to have a detrimental effect on the neuropsychological development of the infants. This, as we will discuss later, might be explained by the protective effects of maternal fish consumption, the main source of mercury in this cohort, among other factors ${ }^{26}$. In relation to prenatal low exposure to other metals and 
early neuropsychological development, the INMA project provided evidence of no associations.

\section{Outdoor air pollution}

Outdoor air pollution is a global public health threat. Animal studies have shown that air pollutants might reach the brain directly via the olfactory bulb and may themselves be proinflammatory ${ }^{27}$. However, research on the neuropsychological effects in humans, particularly in children, only started some years ago. A study including 1889 children from the four youngest INMA cohorts observed an inverse non-significant association between prenatal exposure to $\mathrm{NO}_{2}$ and benzene and mental development at the age of 14 months ${ }^{28,29}$. The associations were stronger among children whose mothers reported low intakes of fruits/vegetables during pregnancy ${ }^{28}$. In children from Gipuzkoa cohort it was also found an inverse association between prenatal $\mathrm{PM}_{2.5}$ exposure and the scores obtained for psychomotor development $\left[\beta(90 \% \mathrm{CI})=-1.14(-1.75,-0.53)\right.$ for a $1 \mu \mathrm{g} / \mathrm{m}^{3}$ increase of $\left.\mathrm{PM}_{2.5}\right]^{29}$. In 2014 Guxens et al. expanded the work to 6 European birth cohorts including new data from INMA ${ }^{30}$. The study, including more than 9000 children, observed that $\mathrm{NO}_{2}$ exposure during pregnancy was associated with reduced psychomotor development $\left[\beta(95 \% \mathrm{CI})=-0.68(-1.25,-0.11)\right.$ per increase of $10 \mu \mathrm{g} / \mathrm{m}^{3}$ in $\mathrm{NO}_{2}$ ], with similar trends in most European regions. The study did not observe associations with cognitive development or between other air pollutants $\left(\mathrm{NO}_{\mathrm{x}}, \mathrm{PM}_{2.5}\right.$, $\left.\mathrm{PM}_{10}, \mathrm{PM}_{\text {coarse }}\right)$ and several neuropsychological domains evaluated between 1 and 6 years of age $\mathrm{e}^{30}$. Guxens et al. also evaluated the association between these air pollutants and autistic traits in a study including more than 8000 children from four to ten years of age in four European birth cohorts and no associations were observed ${ }^{31}$ (Table 2). Overall, the INMA project, together with other birth cohorts in Europe, has shown a 
consistent association between air pollutants, particularly $\mathrm{NO}_{2}$, a marker of traffic related air pollution, and impaired neuropsychological development of children. However, no associations with autistic traits have been described.

\section{Residential indoor air pollution}

In children from the region of Menorca, cognitive functioning and attentionhyperactivity behaviours were evaluated at age 4 years in relation to prenatal use of gas appliances, obtained by questionnaire, and indoor $\mathrm{NO}_{2}$ concentrations at each participant's home ${ }^{32}$. The study found that both use of gas appliances and $\mathrm{NO}_{2}$ concentrations were inversely associated with cognitive outcomes $[\beta(95 \% \mathrm{CI})$ for general cognition $=-5.10(-9.92,-0.28)$ and $=-0.27(-0.48,-0.07$, respectively] and ADHD symptoms [OR (95\%CI) for inattention symptoms=3.59 $(1.14,11.33)]$ and 1.06 , $(1.01,1.12)]^{32}$. A second study, including more than 1800 children of 14 months of age, observed that children whose mothers used gas cooking during pregnancy had a small decrease in the mental development score compared with those using other cookers $[\beta$ $(95 \% \mathrm{CI})=-2.5$ points $(-4.0,-0.9)]^{33}$. This decrease was stronger when gas cooking was combined with less frequent use of an extractor fan, and was relatively consistent across strata defined by social class, education, among other covariates $^{33}$ (Table 2). The INMA data published on indoor air pollution are consistent with those obtained for outdoor air pollution, although few papers have been published within the same project.

\section{Smoking}

Cigarette smoking reduces the health of smokers but also of those exposed to secondhand smoking ${ }^{34}$. Association between maternal smoking during pregnancy with the neuropsychological development of children at age 4 were evaluated in the region of 
Menorca $^{35}$. In this study, maternal smoking (in cigarettes/day) was associated with a decrease of children's general cognitive development $[\beta(95 \% \mathrm{CI})=-0.60(-1.10,-0.09)]$, as well as other subareas of the test (verbal, quantitative, working memory and executive function scores). An extension of this study observed this association was modified by a polymorphism in the GSTM1 gene, being children with null allele for this gene those who had the strongest effects (beta $=-4.73$, 95\% CI -9.45 to -0.02$)^{36}$ (Table 2).

\section{Maternal fish intake}

Fish is an important source of n-3 fatty acids, iodine, vitamin D, and other nutrients which are essential for brain development but is also a potential source of neurotoxins, such as POPs or methylmercury ${ }^{37}$. Fish consumption during pregnancy and during childhood was obtained in INMA through semi-quantitative food frequency questionnaires. In the cohort of Menorca no associations were observed between maternal fish consumption and the scores obtained in the MSCA at 4 years of age ${ }^{38}$. However, among children breastfed for $<6$ months, maternal fish intakes of $>2-3$ times/week (but not $>3$ times/week) were associated with significantly higher scores on several subscales compared with maternal intakes of $\leq 1$ time/week [e.g. $\beta$ $(95 \% \mathrm{CI})=11.0(5.017 .1)$ of the general cognitive score $]^{38}$. A second study including more than 1500 children observed that consumption of seafood during pregnancy was associated with increments in neuropsychological scores, although the associations were not fully linear ${ }^{26}$. The intake of 600 and $854 \mathrm{~g} /$ week increased $2.90(0.72,5.09)$ points in the cognitive development at the age of 14 months and $2.84(0.74,4.94)$ at the age of 4-5 years. For consumptions above 854 g/week associations were weaker. Intake of small fatty fish explained part of the positive associations at 14 months of age, and lean 
and large fatty fish appeared to be predictors of child neuropsychological function the age of 4-5 years. Additionally, the study observed a reduction in autistic traits in relation to total, lean, and large fatty fish consumption [> $854 \mathrm{~g} /$ week of total fish maternal consumption decreased $-0.55(-1.06,-0.04)$ points of autism-spectrum traits]. Overall, coefficients diminished 15\%-30\% after adjustment for mercury exposure or long-chain polyunsaturated fatty acid concentrations in cord blood ${ }^{26}$ (Table 2). Studies from the INMA project show the potential benefits of balanced consumption of fish, and that these might be more evident in children breastfeeding less time than what is established by the current recommendations.

\section{Maternal dietetic supplements intake}

Folic acid supplements intake during pregnancy are recommended in order to reduce the incidence of neural tube defects and improve overall foetal growth. In fact, some studies indicate that a dose of $400 \mu \mathrm{g} /$ day of folic acid is needed to avoid neural tube defects ${ }^{39}$. In a study conducted in Menorca, the use of folic acid during pregnancy was associated with higher subscale scores for verbal $[\beta(\mathrm{SE})=3.98(1.69)]$, motor $[\beta(\mathrm{SE})=4.54$ (1.66)] and verbal-executive function $[\beta(\mathrm{SE})=3.97(1.68)]$ subscales at the age of 4 years $^{40}$. Also, teacher ratings for social competence $[\beta(\mathrm{SE})=3.97(1.61)]$ and inattention symptoms $[\mathrm{OR}(95 \% \mathrm{CI})=0.46(0.22,0.95)]$ were associated with the folic acid intake, independently of the intake of other vitamins ${ }^{40}$. Detailed information on the daily doses of folic acid supplements was gathered from the mothers to assess a doseresponse analysis in a second study ${ }^{41}$. Authors observed that, at the age of 1 year, children whose mothers used folic acid supplement dosages higher than $5000 \mu \mathrm{g} /$ day during pregnancy had a statistically significantly lower mean psychomotor scale score $[\beta(95 \% \mathrm{CI})=-4.35(-8.34,-0.36)]$ than children whose mothers used a recommended 
dosage of folic acid supplements (400-1000 $\mu \mathrm{g} /$ day). An increased risk of delayed psychomotor development (psychomotor scale score <85) was also evident among children whose mothers took folic acid supplement dosages higher than $5000 \mu \mathrm{g} / \mathrm{day}$, although the association was not statistically significant [OR $(95 \% \mathrm{CI})=1.59(0.82$, 3.08)]. Regarding intakes $<400 \mu \mathrm{g} /$ day children obtained better mental scores $[\beta$ $(95 \% \mathrm{CI})=2.30(0.38,4.22)]$ than those of mothers who ingested between 400 and 1000 $\mu \mathrm{g} / \mathrm{day}^{41}$ (Table 2). These results suggested that high folic acid supplementation ( $\geq 5000$ $\mu \mathrm{g} /$ day) could be harmful for child neuropsychological development but it should be confirmed in further studies.

In the INMA project two studies have evaluated the effects of iodine supplementation during pregnancy ${ }^{42,43}$, which is often recommended in order to ensure a proper thyroid function (the WHO recommends a iodine intake for pregnant and lactating women of $250 \mu \mathrm{g} /$ day if iodized salt is not accessible for around of the $80 \%$ of the households ${ }^{44}$ ). In the birth cohort of Valencia, maternal intake of $\geq 150 \mu \mathrm{g} /$ day of iodine supplements, compared with $<100 \mu \mathrm{g} /$ day, was associated with a 5.2-point decrease in psychomotor development $(95 \% \mathrm{CI}=-8.1,-2.2)$ at the age of $1 \mathrm{year}^{42}$. However, when the analyses were extended to other cohorts, the association was not statistically significant $[\beta$ $(95 \% \mathrm{CI})=-0.9(-6.9,5.0)$ for psychomotor score, and a decrease of 1.8 point in mental score was observed $(95 \% \mathrm{CI}=-5.6,2.0)]$ at the age of 1 year ${ }^{43}$. The results of these studies indicate that, at least in these Spanish regions, iodine supplementation does not improve infant neuropsychological development in the first year of life (Table 2).

Maternal thyroid hormone levels 
Maternal thyroid hormones play an important role in many fundamental processes underlying brain development and maturation of the fetus ${ }^{45}$. In Granada birth cohort, which only includes boys, higher thyroid-stimulating hormone (TSH) cord blood concentrations were associated with a decrease of 3.51 and 3.15 points on cognitive and executive function scores, respectively, and an increased risk of scoring low in the quantitative scale at the age of 4 years $[\mathrm{OR}(95 \% \mathrm{CI})=2.64(1.16,5.54)]^{46}$. In a second study including more than 1700 children, low free thyroxine (fT4) levels $(<5$ th percentile) in healthy pregnant women were associated with a moderate delay in child neurodevelopment $[\beta(95 \% \mathrm{CI})=-3.4(-6.7,-0.2) \text { points of mental scores of the BSID }]^{47}$. Self-reported prepregnancy thyroid disorder without medical treatment was also associated with child neurodevelopment $[\beta(95 \% \mathrm{CI})=-5.5(-8.9,-2.0)$ points of mental scores of the BSID] $]^{47}$ (Table 2).

\section{Vitamin D}

Vitamin D has a crucial role in maintaining the musculoskeletal health and also has influences on the immune system and brain development and maintenance ${ }^{48}$. In 2012 Morales et al. observed that increasing circulating concentration of maternal vitamin D during pregnancy was associated with improved mental $[\beta(95 \% \mathrm{CI})=0.79(0.14,1.45)]$ and psychomotor $[\beta(95 \% \mathrm{CI})=0.88(0.22,1.54)]$ development in 1820 infants of 1 year $^{49}$. Moreover, infants of mothers with vitamin $D$ concentrations $>30 \mathrm{ng} / \mathrm{mL}$ (clinically considered as optimal levels) showed an advantage of 2.6 and 2.3 points in mental and psychomotor scores, respectively, in comparison with those of mothers with vitamin D concentrations $<20 \mathrm{ng} / \mathrm{mL}$ (considered as deficient levels) ${ }^{49}$. Three years later, in a study including 1650 children, Morales et al. observed that prenatal vitamin D concentrations were also associated with a reduced risk of total ADHD-like symptoms 
in children at the age of 4 years [IRR $(95 \% \mathrm{CI})=0.89(0.80,0.98)$ per $10 \mathrm{ng} / \mathrm{ml}$ increment of maternal vitamin $\mathrm{D}]^{50}$. Using clinical cut-off points, the risk of ADHD DSM-IV was of RR $(95 \% \mathrm{CI})=0.87(0.72,1.06)$ per $10 \mathrm{ng} / \mathrm{ml}$ increment of vitamin $\mathrm{D}^{50}$ (Table 2). Above results indicate neuropsychological benefits by increasing vitamin D levels up to those clinically considered as optimal.

\section{Phthalates and Bisphenol A (BPA)}

Phthalates and BPA are non-persistent compounds that have been suggested to have effects on the neuropsychological development, based on some animal and child studies, but results are not consistent and there are still discrepancies among them ${ }^{51,52}$. The INMA project has been the first birth cohort to use two biological samples in order to measure phthalates and BPA exposure during pregnancy, reducing potential misclassification, in relation to different neuropsychological items (mental, psychomotor and behavioural) in children at different ages (1, 4 and 7 years). Results have not provide consistent associations across ages ${ }^{51,52}$. For instance, the study evaluating the effects of exposure to low and high molecular weight phthalates only observed an association between prenatal MBzP phthalate exposure and psychomotor score at the age of 4 years $[\beta(95 \% \mathrm{CI})=-1.49(-2.78,-0.21)]$ but not with the cognitive domain in children at the age of both 1 and 4 years $^{52}$. Associations between DEHPs concentrations and social competence, ADHD symptoms or behavioural outcomes were also inconsistent across ages. Furthermore, there were few associations showing increasing scores with increasing exposure to some of the compounds analyzed ${ }^{52}$. The study evaluating effects of prenatal BPA exposure observed a decreased on 
psychomotor development at the age of 1 year $[\beta(95 \% \mathrm{CI})$, comparing tertiles $=-4.28(-$ $8.15,-0.41)]$, but not at the age of $4[\beta(95 \% \mathrm{CI})=2.50(-1.18,6.18)]$, and an increased in hyperactivity at the age of 4 years $[\operatorname{IRR}(95 \% \mathrm{CI})=1.72(1.08,2.73)]$ that did not occur at the age of $7[\operatorname{IRR}(95 \% \mathrm{CI})=0.97(0.63,1.49)]^{51}$ (Table 2).

\section{Other determinants}

The INMA project has also evaluated other potential determinants of the neuropsychological development in children such as maternal intelligence ${ }^{53}$ and weight $^{54}$, head circumference during pregnancy ${ }^{55}$, prenatal exposure to other endocrine disruptors $^{56}$, the use of non-persistent pesticides at home ${ }^{57}$, the presence of dampness, pet ownership and farm animal at home ${ }^{58}$ and the use of cell phones (electromagnetic radiation exposure) during pregnancy ${ }^{59}$ (Table 2).

A study including the children from Sabadell birth cohort observed that maternal IQ plays an important role in the first stages of cognitive development in children of more disadvantaged occupational social classes, but that for other groups the effects of maternal IQ on cognitive development were mostly explained by maternal education ${ }^{53}$. Maternal pre-pregnancy obesity was associated with reduced infant cognitive development at the age of 14 months [score reduction $(95 \% \mathrm{CI})=2.72(-5.35,-0.10)]^{54}$ in a study including more than 2000 Spanish children and around 400 Greek children. This association showed a dose-response relationship with continuous maternal body mass index (BMI), whereas no associations with paternal overweight/obesity were observed ${ }^{54}$ (Table 2). Besides, in another study prenatal and perinatal head circumference of children was not associated with mental and psychomotor scores at the age of 14 
months, suggesting that head circumference growth during uterine life among healthy infants may not be an important marker of early-life neuropsychological development ${ }^{55}$.

Neuropsychological effects of in utero exposure to mixtures of xenoestrogens were evaluated in a study involving 489 children $^{56}$. Total Effective Xenoestrogen Burden (TEXB), a quantitative biomarker of the cumulative effect of xenoestrogens measured in placentas, was not associate with mental development at the age of 14 months [ $\beta$ $(95 \% \mathrm{CI})=0.48$ (2.23), $\mathrm{p}$-val=0.83], and only boys with the highest TEXB levels scored on average 5.2 points less than those with the lowest, on psychomotor development at 14 months $[\beta(95 \% \mathrm{CI})=-5.19$ (2.65), $\mathrm{p}$-val=0.05]. These associations did not persist at the age of 4 years $^{56}$ (Table 2).

The use of non-persistent pesticides at home during pregnancy has been obtained in INMA through questionnaires ${ }^{57}$. Researchers observed that the use of insecticide sprays during pregnancy was associated with a decrement in psychomotor development $[\beta$ $(95 \% \mathrm{CI})=-1.9(-3.4,-0.5)]$ during the first year of life. These negative effects were enhanced in girls and in children with higher levels of prenatal PCB and mercury exposure and belonging to the lowest social class ${ }^{57}$ (Table 2).

Another study collecting information on pet ownership, as a marker of exposure to allergens, during pregnancy in the Menorca birth cohort showed no associations with cognitive and psychomotor development or social competence at the age of 4 years ${ }^{58}$ (Table 2). 
Finally, a study including participants from Sabadell evaluated whether the use of cell phones during pregnancy had an impact on the neuropsychological development of children at the age of 14 months ${ }^{59}$. The study observed no association between cell phone use and mental $[\beta(95 \% \mathrm{CI})=0.8(-0.6,2.2)]$ or psychomotor development scores $[\beta(95 \% \mathrm{CI})=-0.8(-2.2,0.6)]$. Furthermore, there was no trend with amount of cell phone use within users ${ }^{59}$ (Table 2).

\section{Postnatal determinants}

Persistent organic pollutants

Postnatal exposure to POPs in INMA cohorts has been evaluated in a lesser extent compared to prenatal exposure. PCBs exposure, measured at the age of 4 years ( $\mathrm{N}=285$ ), did not showed any associations with the cognitive or psychomotor development ${ }^{18}$. Another study estimating postnatal exposure to PCB153, DDE and HCB through PBPK models ( $\mathrm{N}=1175)$ showed that although breastfeeding increased children's blood POPs levels during postnatal life, deleterious effects of PCB153 on neuropsychological development in the first year of life were mainly attributable to prenatal exposure ${ }^{60}$. In addition, postnatal exposure to PBDE47 (244 children were classified as exposed according to the limit of quantification) was not associated with cognitive development at the age of 4 years $^{21}$. However, higher exposure was related with a higher risk of attention deficit problems $[\mathrm{RR}(95 \% \mathrm{CI})=1.8(1.0,3.2)]$ and poor social competence $[\mathrm{RR}(95 \% \mathrm{CI})=2.6(1.2,5.9)]^{21}$ (Table 3).

Metals 
Granada cohort evaluated the effects of postnatal exposure to metals on cognitive development of children in a cross-sectional study ${ }^{61}$. After adjustment for fish intake, increasing total mercury levels measured in 72 children's hair at the age of 4 years were associated with decrements in the general cognitive $[\beta(95 \% \mathrm{CI})=-6.6$ points $(-13.04$, $0.15)]$, memory $[-8.4$ points $(-15.96,-0.83)]$, and verbal $[-7.5$ points $(-14.99,-0.02)]$ scores $^{61}$ (Table 3).

\section{Outdoor air pollution}

Granada cohort also evaluated the potential detrimental effects of outdoor air pollution on neuropsychological development of children ${ }^{62}$. The study, including 210 children, observed a decrease of 4.19 points in the general cognitive score and decreases of 6.71, 7.37 and 8.61 points in quantitative, working memory and gross motor areas, respectively, in relation to $\mathrm{NO}_{2}$ levels assessed during their fifth year of life. However, most of associations were not statistically significant ${ }^{62}$ (Table 3).

\section{Smoking}

The relation between postnatal maternal smoking and neuropsychological development of INMA children has been also evaluated ${ }^{35}$. The study included mothers that smoked both during pregnancy and after birth and mothers that only smoked in one of these periods $(\mathrm{N}=420)$, and observed no associations between smoking and their child cognition, at the age of 4 years, among mothers smoking only after birth ${ }^{35}$ (Table 3).

\section{Breastfeeding}

INMA studies have reported the health benefits of breastfeeding in a number of studies. The first, conducted in the Ribera d'Ebre birth cohort, showed that at the age of 13 
months the mental (10.71 points) and the psychomotor (8.97 points) development of children breastfeeding for more than 16 weeks was better compared to those breastfeeding for a shorter period of time ${ }^{15}$. When children of Ribera d'Ebre and Menorca became 4 years, breastfeeding for a period longer than 28 weeks was also associated with better cognitive scores $[\beta(95 \% \mathrm{CI})$ for general cognition $=3.9(0.0$, 7.9)] $]^{8}$. Furthermore, breastfeeding was shown to counterbalance the detrimental effects of prenatal DDE/DDT exposure in two INMA studies ${ }^{15,63}$. Also, the benefits of breastfeeding on cognitive and executive function were described to be stronger in children whose mothers had lower education level $(\beta=7.02)$ compared to those with a higher education level $(\beta=2.59)^{8}$. Results also showed benefits of breastfeeding on social competence $[\mathrm{RR}(95 \% \mathrm{CI})$ for poor social competence $=0.44(0.27,0.72)]$ and attention and hyperactivity symptoms $[\mathrm{RR}(95 \% \mathrm{CI})=0.61(0.44,0.86)]^{8}$. In the birth cohort of Sabadell the benefits of breastfeeding were only statistically significantly associated to mental score at 14 months among those children breastfeeding for a longer time and with a higher n3/n6 colostrum long-chain polyunsaturated fatty acid (LCPUFA) ratio $\left[(\beta \quad(95 \% \mathrm{CI})=5.50(1.05,9.94)]^{64}\right.$. No relation was found between breastfeeding and psychomotor score ${ }^{64}$. At the age of 4 years of these children, full breastfeeding (above 6 months) was associated with child general cognitive $[\beta$ $(95 \% \mathrm{CI})=7.5(2.9,12.1)]$ and executive function $[\beta(95 \% \mathrm{CI})=6.9(2.1,11.7)]$ after adjusting for a range of social, psychological, and nutritional factors ${ }^{65}$. However, omega-3 (n3) fatty acid levels were not associated with child neuropsychological scores $^{65}$. Menorca and Sabadell birth cohorts analysed polymorphisms in genes encoding the key enzymes involved in LC-PUFA synthesis in mothers and their offspring $^{66}$. The study observed maternal genetic variants involved in colostrum n-3 LC-PUFA levels, associated with higher cognitive scores in their children. In infants, 
the study found that certain genetic variants modified the effects of breastfeeding on cognition, confirming gene-breastfeeding interactions ${ }^{66}$ (Table 3).

$B P A$

A cross-sectional study conducted in Granada ( $\mathrm{N}=269$ boys) observed that at the age of 9-11 years higher urinary BPA concentrations (only one sample) were associated with lower behavioural scores on some of the Child Behaviour Checklist (CBCL/6-18) scales (somatic complaints and social and thought problems), but no associations were observed with other scores, including ADHD problems ${ }^{67}$ (not shown in tables).

\section{Other determinants}

Postnatal use of non-persistent pesticides at home did not associate with the mental or psychomotor development of children at the age of 1 year in a study including more than 2000 mother-children pairs ${ }^{57}$ (Table 3).

In relation to home conditions, persistent home dampness during early life significantly decreased the general cognitive score by 4.9 points $(95 \% \mathrm{CI}=-8.9,-0.8)$ and the social competence by 6.5 points (95\% CI=-12.2, -0.9) at the age of 4 years in the birth cohort of Menorca ${ }^{58}$. However, pet ownership and the measured microbial compounds at the age of 3 months were not related with the psychometric tests scores. On the contrary, occasional farm animal contact increased the general cognitive score $[\beta(95 \% \mathrm{CI})=5.6$ $(1.8,9.3)]^{58}$ (Table 3). 
The effects of radiofrequency electromagnetic fields (non-ionizing radiation) were cross-sectionally evaluated in a subsample of boys of the Granada birth cohort at the age of 9-11 years ${ }^{68}$. The study observed that all exposure measurements were lower than reference guideline limits. Additionally, for most of the cognitive and behavioural parameters no associations were observed; only children living in areas with radiofrequency-electromagnetic fields exposure above median levels had statistically significant lower scores for verbal expression/comprehension and higher scores for internalizing and total problems, and obsessive-compulsive and post-traumatic stress disorders, in comparison to those living in areas with lower exposure ${ }^{68}$ (not shown in tables).

Finally, the INMA project also evaluated the relationship between stress (using cortisol in saliva of children as biomarker), and neuropsychological development at the age of 14 months $^{69}$. Forns et al. observed that higher levels of cortisol were associated with better scores in the mental scale [children in the highest tertile of cortisol levels had higher scores compared with the reference group $(\beta=4.60$; $p$-value $=0.03)]^{69}$.

\section{Comorbidities}

The INMA project has also investigated the link between different health outcomes in order to better understand whether these are correlated as well as the potential mechanisms of the associations observed with certain exposures. In relation to neuropsychological development, studies have evaluated its link with thyroid hormones, atopic disorders and weight status of children. 
A cross-sectional study conducted in the birth cohorts of Menorca and Ribera d'Ebre observed that at the age of 4 years $(\mathrm{N}=342)$, children with TSH concentrations in the upper quartile of the normal range performed lower on cognitive scores and were at higher risk for attention deficit and hyperactivity/impulsivity symptoms compared to those in the lower quartile ${ }^{70}$. In contrast, high free T4 concentrations were associated with decreased risk of having 1-5 attention deficit symptoms $[\mathrm{OR}=0.25 ; \mathrm{p}<0.01)]^{70}$. Similar results were found in the cohort of Granada with a cross-sectional study, including 300 boys at 10 years of age; children with TSH levels in the higher tertile had worse verbal memory, whereas children with higher free T4 levels had better attention, lower impulsivity and better cognitive scores ${ }^{71}$.

Other studies focused on the association between atopy and related outcomes and neuropsychological development ${ }^{72,73}$. Thus, in almost 400 children from Menorca 4 years old, it was observed that only eczema was associated with social competence at that age [general cognitive score, RR $(95 \% \mathrm{CI})=1.99(1.07,3.69)]$. No associations with other atopy related symptoms (asthma, wheeze, rhinitis or atopy) were observed, neither with general cognition ${ }^{72}$. However, atopy, asthma, and wheeze at age 6 years were associated with cognitive development at age 4 years $[\mathrm{RR}(95 \% \mathrm{CI})=2.46(1.31,4.62)$ for atopy] and eczema with social competence $[\mathrm{RR}(95 \% \mathrm{CI})=2.14(1.45,3.15)]^{72}$. In the same cohort associations between genes related to atopy and neuropsychological development was observed $^{73}$, but the associations observed between certain environmental pollutants and cognitive development were not explained by the immunological status (atopy) of the children ${ }^{73}$. 
The relationship between child weight and neuropsychological development has been also evaluated within the INMA project. Guxens et al. investigated the association between neuropsychological development at the age of 4 years and overweight at the age 6 years in the birth cohort of Menorca with a cross-sectional design ${ }^{74}$. Although authors did not observe a relation between cognitive function scores and concurrent measures of BMI at age 4 years, higher general cognitive abilities at age 4 years, particularly executive function, verbal, quantitative, and memory skills scores, were associated with a lower likelihood of being overweight at age 6 years, after adjustment for a large list of covariates, including socioeconomic factors and maternal BMI [OR $(985 \% \mathrm{CI})=0.47(0.25,0.88)$ for general cognitive score]. Furthermore, the risk of maintaining an unhealthy weight status (at risk of overweight or overweight) between 4 and 6 years of age, as well as of worsening their weight status over time (incidence of being at risk of overweight or overweight) was lower among children with better cognitive scores at age 4 years ${ }^{74}$.

\section{Discussion}

The current review provides an overview of the main determinants of child's neuropsychological development studied within the INMA project and the main findings obtained, related with prenatal and postnatal exposures to maternal, environmental and dietary determinants and co-morbidities.

In terms of the environmental pollutants, INMA has provided substantial evidence for the inclusion of DDT in the current list of known developmental neurotoxicants ${ }^{4}$. In addition, our data have provided new knowledge on the relation between urban air pollution and impaired neurodevelopment, specially on executive functions, motor 
development and attention and autism spectrum effects ${ }^{27}$. This is a very relevant area of research given the health burden of urban air pollution ${ }^{75}$. INMA project has also contributed to show the detrimental influence of certain indoor air pollutants.

Furthermore, INMA is a very pertinent cohort to assess the effects of fish consumption and related pollutants, given the high and variable intake among the Spanish population, and some micronutrients. Thus, our results have shown that a balanced maternal fish intake could protect from the potential adverse effects of prenatal exposure to mercury. The longitudinal nature of INMA will allow the following up for a potential delayed relationship between prenatal exposure and neurodevelopment as well as the role of other factors (diet, co-exposures or genetics) on it.

We have also found an important deficit of Vitamin D, with a high prevalence in a sunny country due to the current dominant indoor lifestyle. This issue raises an important public health concern that merits promoting global preventive interventions. The project has also contributed to the understanding of the role of breastfeeding on the neuropsychological benefits.

The results relating exposure to non-persistent contaminants (such as BPA, phthalates, non-persistent pesticides) and neurodevelopment are still scarce and less consistent, not only within the INMA birth cohort but also in other studies, mainly because proper exposure assessment to these compounds is much more complicated, due to their exposure is highly changing along short periods of time ${ }^{76-78}$. Nevertheless, the INMA study has been one of the pioneering cohorts to evaluate these compounds and to study their association with neuropsychological impairment. 
Interesting data have also been revealed concerning critical windows of exposure. During prenatal period, when brain structures are forming and growing considerably, the effect of environmental exposures may be more important than exposures during postnatal life. Thus, INMA project has contributed to provide increasing evidence of the association between prenatal exposure to urban air pollutnats and impaired neurodevelopment, as well as for exposure to some POPs. Using innovative methodologies $^{60}$, INMA cohort data have shown that postnatal exposure to POPs compounds does not seem to play a role on this association and that the critical period of exposure during prenatal life. The identification of critical periods of exposure is fundamental for preventive purposes; however, to date, the windows of sensitivity to environmental exposures, air pollution for example, are still unknown ${ }^{79}$. The review also highlights the amount of information that has been gathered within the project and can be used to answer current or new research questions, especially of in relation to postnatal exposures.

Most of the research included in this review has been limited to hypothesis testing studies based on individual exposures of interest. The future work of the INMA Project, as part of the HELIX project ${ }^{80}$, will focus in the analysis of the exposome. The exposome has been proposed as a new paradigm to encompass the totality of human environmental (meaning all non-genetic) exposures from conception to old ages ${ }^{80,81}$. In addition, taking profit of all the information gathered on neuropsychological development, we also aim to evaluate the relationship between the neuropsychological evaluations conducted at each year of follow-up in order to establish individual trajectories of cognitive growth and measure changes in the growth function underlying 
the brain development. Thirdly, we will evaluate comorbidities by assessing the relationship between neuropsychological development, atopy, and obesity using information obtained at different time-points, including biomarkers of metabolic syndrome as well. A final new line of research refers to the assessment of the effect of the economical crisis doing pre-post studies, including social determinants, diet, exercise, and stress given the dramatic changes that had occurred after the period 201015.

\section{Conclusions}

The updated findings presented in this Review confirm and add evidence of the role of a range of maternal and environmental exposures on early childhood neuropsychological development. The findings underscore the importance of continued research on the delineation of the sensitive windows of exposure during pregnancy and postnatally and on the combined effects of toxicant exposures, denoted the exposome, since environmental exposure to multiple pollutants are the norm rather than the exception. In terms of health policy, these findings have important implications for the development of public health policies to advance the health and development of children.

\section{Acknowledgments}

The authors are indebted to all participants, without whom this work would not have been possible. We are grateful to all the personnel that have made INMA Project a reality.

\section{Funding}


This study was supported Instituto de Salud Carlos III (Red INMA G03/176, CB06/02/0041, 97/0588, 00/0021-2, PI04/1436, PI06/1756, PI08/1151, PS09/01958, PI12/01890, PI14/00677, MS13/00054, CP13/00054 including FIS-FEDER funds 03/1615, 04/1509, 04/1112, 04/1931, 05/1079, 05/1052, 06/1213, 07/0314, 09/02311, 09/02647, 11/0178, 11/02591, 11/02038, 13/1944, 13/2032, 13/02429, 14/0891, 14/1687, and 16/1288) and Miguel Servet-FEDER MS15/00025, Spanish Ministry of Health - CIBERESP (FIS-97/1102, FIS-PS09/00362, FIS-07/0252, FIS-PI11/00610, FISPI07/0252, FISPI11/0610, FIS-PI04/2018, FIS-PI09/02311, FIS-PI13/02429, FISPI06/0867, FIS-PS09/00090, FIS-PI13/02187, PI13/02406, MS13/00054), Spanish Ministry of Economy and Competitiveness (SAF2012-32991 incl. FEDER funds), EU Comission (QLK4-CT-2000-00263, QLK4-1999-01422, QLK4-2002-00603 and CONTAMED FP7-ENV-212502, FP7-ENV-2011 cod 282957, 261357, 308333 and 603794 and HEALTH.2010.2.4.5-1), Generalitat de Catalunya-CIRIT 1999SGR 00241, Generalitat de Catalunya-AGAUR (2009 SGR501, 2014 SGR 822), Department of Health of the Basque Government (2005111093, 2009111069, 2013111089 and 2015111065), the Provincial Government of Gipuzkoa (DFG06/002, DFG08/001 and DFG15/221), Consejería de Salud de la Junta de Andalucía (grant number 183/07 and SAS-PI-0675-2010), Conselleria de Sanitat, Generalitat Valenciana, Andalusia Regional Government - Consejería de Salud (Grants P09-CTS-5488 Project of Excellence, and SAS PI-0133-2007; PI-0675-2010), Agence Nationale de Securite Sanitaire de l'Alimentation de l'Environnement et du Travail (1262C0010), beca de la IV convocatoria de Ayudas a la Investigación en Enfermedades Neurodegenerativas de La Caixa, Fundació La Caixa (97/009-00 and 00/077-00), Fundació La Marató de TV3 (090430), Obra Social Cajastur/Fundación Liberbank and University of Oviedo, and 
annual agreements with the municipalities of the area of study (Zumarraga, Urretxu , Legazpi, Azkoitia y Azpeitia y Beasain).

\section{References}

1. Ramón R, Ballester F, Rebagliato M, et al. [The Environment and Childhood Research Network ('INMA' network): study protocol]. Rev española salud pública. Jan;79(2):203-20.

2. Ribas-Fito N, Ramon R, Ballester F, et al. Child health and the environment: the INMA Spanish Study. PaediatrPerinatEpidemiol. 2006 Sep;20(0269-5022 (Print)):403-410.

3. Guxens M, Ballester F, Espada M, et al. Cohort Profile: The INMA--INfancia y Medio Ambiente--(Environment and Childhood) Project. IntJEpidemiol. 2012 Aug;41(1464-3685 (Electronic)):930-940.

4. Grandjean P, Landrigan PJ. Neurobehavioural effects of developmental toxicity. Lancet Neurol. 2014 Mar;13(3):330-8.

5. Bayley N. Escalas Bayley de Desarrollo Infantil [Bayley Scales of Infant Development] . Madrid : TEA Ediciones; 1977.

6. Griffiths R. The Griffiths Mental Development Scales. Oxon, England: The Test Agency Limited; 1996.

7. McCarthy D. Manual for the McCarthy scales of children's abilities. New York: Psycological Corp; 1972.

8. Julvez J, Ribas-Fito N, Forns M, Garcia-Esteban R, Torrent M, Sunyer J. Attention behaviour and hyperactivity at age 4 and duration of breast-feeding. Acta Paediatr. 2007 Jun;96(0803-5253 (Print)):842-847.

9. Julvez J, Forns M, Ribas-Fito N, et al. Psychometric Characteristics of the California Preschool Social Competence Scale in a Spanish Population Sample. Early Educ Dev. 2008;19(5):795-815.

10. Scott FJ, Baron-Cohen S, Bolton P, Brayne C. The CAST (Childhood Asperger Syndrome Test): preliminary development of a UK screen for mainstream primary-school-age children. Autism. 2002 Mar;6(1):9-31.

11. Goodman R. The Strengths and Difficulties Questionnaire: a research note. $J$ Child Psychol Psychiatry. 1997 Jul;38(5):581-6.

12. Gianarris WJ, Golden CJ, Greene L. The Conners’ Parent Rating Scales: a critical review of the literature. Clin Psychol Rev. 2001 Oct;21(7):1061-93.

13. Hudziak JJ, Wadsworth ME, Heath AC, Achenbach TM. Latent class analysis of Child Behavior Checklist attention problems. J Am Acad Child Adolesc Psychiatry. 1999 Aug;38(8):985-91.

14. Convention S of the S. Stockholm Convention on Persistent Organic Pollutants (POPs) [Internet]. http://chm.pops.int 2008. Available from: http://chm.pops.int

15. Ribas-Fito N, Cardo E, Sala M, et al. Breastfeeding, exposure to organochlorine compounds, and neurodevelopment in infants. Pediatrics. 2003 May;111(10984275 (Electronic)):e580-e585.

16. Ribas-Fito N, Torrent M, Carrizo D, et al. In utero exposure to background concentrations of DDT and cognitive functioning among preschoolers. Am J Epidemiol. 2006 Nov 15;164(10):955-62.

17. Forns J, Lertxundi N, Aranbarri A, et al. Prenatal exposure to organochlorine 
compounds and neuropsychological development up to two years of life.

EnvironInt. Centre for Research in Environmental Epidemiology (CREAL),

Barcelona, Spain; Hospital del Mar Research Institute (IMIM), Barcelona, Spain;

CIBER Epidemiologia y Salud Publica (CIBERESP), Barcelona, Spain; 2012 Sep;45(1873-6750 (Electronic)):72-77.

18. Forns J, Torrent M, Garcia-Esteban R, et al. Prenatal exposure to polychlorinated biphenyls and child neuropsychological development in 4-year-olds: an analysis per congener and specific cognitive domain. Sci Total Environ. 2012 Aug 15;432:338-43.

19. Ribas-Fito N, Torrent M, Carrizo D, Julvez J, Grimalt JO, Sunyer J. Exposure to hexachlorobenzene during pregnancy and children's social behavior at 4 years of age. Env Heal Perspect. 2007 Mar;115(0091-6765 (Print)):447-450.

20. Puertas R, Lopez-Espinosa MJ, Cruz F, et al. Prenatal exposure to mirex impairs neurodevelopment at age of 4 years. Neurotoxicology. Department of Personality, Evaluation and Psychological Treatment, School of Psychology, University of Granada, Spain; 2010 Jan;31(1872-9711 (Electronic)):154-160.

21. Gascon M, Vrijheid M, Martinez D, et al. Effects of pre and postnatal exposure to low levels of polybromodiphenyl ethers on neurodevelopment and thyroid hormone levels at 4years of age. EnvironInt. 2011 Apr;37(1873-6750 (Electronic)):605-611.

22. Gascon M, Fort M, Martínez D, et al. Polybrominated diphenyl ethers (PBDEs) in breast milk and neuropsychological development in infants. Environ Health Perspect. 2012 Dec;120(12):1760-5.

23. Ramon R, Murcia M, Aguinagalde X, et al. Prenatal mercury exposure in a multicenter cohort study in Spain. Environ Int. 2011 Apr;37(3):597-604.

24. Llop S, Guxens M, Murcia M, et al. Prenatal exposure to mercury and infant neurodevelopment in a multicenter cohort in Spain: study of potential modifiers. Am J Epidemiol. 2012 Mar 1;175(5):451-65.

25. Forns J, Fort M, Casas M, et al. Exposure to metals during pregnancy and neuropsychological development at the age of 4 years. Neurotoxicology. 2014 Jan;40:16-22.

26. Julvez J, Méndez M, Fernandez-Barres S, et al. Maternal Consumption of Seafood in Pregnancy and Child Neuropsychological Development: A Longitudinal Study Based on a Population With High Consumption Levels. Am J Epidemiol. 2016 Jan 5;183(3):169-82.

27. Suades-González E, Gascon M, Guxens M, Sunyer J. Air Pollution and Neuropsychological Development: A Review of the Latest Evidence. Endocrinology. 2015 Oct;156(10):3473-82.

28. Guxens M, Aguilera I, Ballester F, et al. Prenatal exposure to residential air pollution and infant mental development: modulation by antioxidants and detoxification factors. EnvironHealth Perspect. 2012 Jan;120(1552-9924 (Electronic)):144-149.

29. Lertxundi A, Baccini M, Lertxundi N, et al. Exposure to fine particle matter, nitrogen dioxide and benzene during pregnancy and cognitive and psychomotor developments in children at 15 months of age. Environ Int. 2015 Jul;80:33-40.

30. Guxens M, Garcia-Esteban R, Giorgis-Allemand L, et al. Air pollution during pregnancy and childhood cognitive and psychomotor development: six European birth cohorts. Epidemiology. 2014 Sep;25(5):636-47.

31. Guxens M, Ghassabian A, Gong T, et al. Air Pollution Exposure during Pregnancy and Childhood Autistic Traits in Four European Population-Based 
Cohort Studies: The ESCAPE Project. Environ Health Perspect. 2016 Jan 12;124(1):133-40.

32. Morales E, Julvez J, Torrent M, et al. Association of early-life exposure to household gas appliances and indoor nitrogen dioxide with cognition and attention behavior in preschoolers. Am J Epidemiol. 2009 Jun 1;169(1476-6256 (Electronic)):1327-1336.

33. Vrijheid M, Martinez D, Aguilera I, et al. Indoor air pollution from gas cooking and infant neurodevelopment. Epidemiology. 2012 Jan;23(1):23-32.

34. Centers for Disease Control and Prevention (CDC). Health Effects of Secondhand Smoke [Internet]. 2016. Available from:

http://www.cdc.gov/tobacco/data_statistics/fact_sheets/secondhand_smoke/healt h_effects/

35. Julvez J, Ribas-Fito N, Torrent M, Forns M, Garcia-Esteban R, Sunyer J. Maternal smoking habits and cognitive development of children at age 4 years in a population-based birth cohort. IntJEpidemiol. 2007 Aug;36(0300-5771 (Print)):825-832.

36. Morales E, Sunyer J, Julvez J, et al. GSTM1 polymorphisms modify the effect of maternal smoking during pregnancy on cognitive functioning in preschoolers. Int J Epidemiol. 2009 Jun;38(3):690-7.

37. Clarkson TW, Strain JJ. Nutritional factors may modify the toxic action of methyl mercury in fish-eating populations. J Nutr. 2003 May;133(5 Suppl 1):1539S-43S.

38. Mendez MA, Torrent M, Julvez J, Ribas-Fitó N, Kogevinas M, Sunyer J. Maternal fish and other seafood intakes during pregnancy and child neurodevelopment at age 4 years. Public Health Nutr. 2009 Oct;12(10):1702-10.

39. Prevention of neural tube defects: results of the Medical Research Council Vitamin Study. MRC Vitamin Study Research Group. Lancet (London, England) [Internet]. 1991 Jul 20;338(8760):131-7. Available from: http://www.ncbi.nlm.nih.gov/pubmed/1677062

40. Julvez J, Fortuny J, Mendez M, Torrent M, Ribas-Fitó N, Sunyer J. Maternal use of folic acid supplements during pregnancy and four-year-old neurodevelopment in a population-based birth cohort. Paediatr Perinat Epidemiol. 2009;23(3):199206.

41. Valera-Gran D, García de la Hera M, Navarrete-Muñoz EM, et al. Folic Acid Supplements During Pregnancy and Child Psychomotor Development After the First Year of Life. JAMA Pediatr. 2014;168(11):e142611.

42. Murcia M, Rebagliato M, Iñiguez $C$, et al. Effect of iodine supplementation during pregnancy on infant neurodevelopment at 1 year of age. Am J Epidemiol. 2011 Apr 1;173(7):804-12.

43. Rebagliato M, Murcia M, Alvarez-Pedrerol M, et al. Iodine Supplementation During Pregnancy and Infant Neuropsychological Development: INMA Mother and Child Cohort Study. Am J Epidemiol. 2013 Apr 1;177(9):944-953.

44. WHO. Iodine supplementation in pregnant and lactating women [Internet]. 2016. Available from: http://www.who.int/elena/titles/guidance_summaries/iodine_pregnancy/en/

45. Moog NK, Entringer S, Heim C, Wadhwa PD, Kathmann N, Buss C. Influence of maternal thyroid hormones during gestation on fetal brain development. Neuroscience. 2015 Oct 3;

46. Freire C, Ramos R, Amaya E, et al. Newborn TSH concentration and its association with cognitive development in healthy boys. Eur J Endocrinol. 2010 
Dec;163(6):901-9.

47. Julvez J, Alvarez-Pedrerol M, Rebagliato M, et al. Thyroxine Levels During Pregnancy in Healthy Women and Early Child Neurodevelopment.

Epidemiology. 2013 Jan;24(1):150-157.

48. Wimalawansa SJ. Vitamin D in the new millennium. Curr Osteoporos Rep. 2012 Mar;10(1):4-15.

49. Morales E, Guxens M, Llop S, et al. Circulating 25-hydroxyvitamin D3 in pregnancy and infant neuropsychological development. Pediatrics. 2012 Oct;130(4):e913-20.

50. Morales E, Julvez J, Torrent M, et al. Vitamin D in Pregnancy and Attention Deficit Hyperactivity Disorder-like Symptoms in Childhood. Epidemiology. 2015 Jul;26(4):458-65.

51. Casas M, Forns J, Martínez D, et al. Exposure to bisphenol A during pregnancy and child neuropsychological development in the INMA-Sabadell cohort. Environ Res. 2015 Oct;142:671-9.

52. Gascon M, Valvi D, Forns J, et al. Prenatal exposure to phthalates and neuropsychological development during childhood. Int J Hyg Environ Health. 2015 Aug;218(6):550-8.

53. Forns J, Julvez J, García-Esteban R, et al. Maternal intelligence-mental health and child neuropsychological development at age 14 months. Gac Sanit. Jan;26(5):397-404.

54. Casas M, Chatzi L, Carsin A-E, et al. Maternal pre-pregnancy overweight and obesity, and child neuropsychological development: two Southern European birth cohort studies. Int J Epidemiol. 2013 Apr;42(2):506-17.

55. Álamo-Junquera D, Sunyer J, Iñiguez C, et al. Prenatal head growth and child neuropsychological development at age 14 months. Am J Obstet Gynecol. 2015 May;212(5):661.e1-11.

56. Vilahur N, Fernández MF, Bustamante M, et al. In utero exposure to mixtures of xenoestrogens and child neuropsychological development. Environ Res. 2014 Oct;134:98-104.

57. Llop S, Julvez J, Fernandez-Somoano A, et al. Prenatal and postnatal insecticide use and infant neuropsychological development in a multicenter birth cohort study. Environ Int. 2013 Jul 2;59C:175-182.

58. Casas L, Torrent M, Zock J-P, et al. Early life exposures to home dampness, pet ownership and farm animal contact and neuropsychological development in 4 year old children: a prospective birth cohort study. Int J Hyg Environ Health. 2013 Nov;216(6):690-7.

59. Vrijheid M, Martinez D, Forns J, et al. Prenatal exposure to cell phone use and neurodevelopment at 14 months. Epidemiology. 2010 Mar;21(2):259-62.

60. Gascon M, Verner M-A, Guxens M, et al. Evaluating the neurotoxic effects of lactational exposure to persistent organic pollutants (POPs) in Spanish children. Neurotoxicology. 2013 Jan 18;34(1872-9711 (Electronic)):9-15.

61. Freire C, Ramos R, Lopez-Espinosa M-J, et al. Hair mercury levels, fish consumption, and cognitive development in preschool children from Granada, Spain . Environ Res. 2010 Jan;110(1):96-104.

62. Freire C, Ramos R, Puertas R, et al. Association of traffic-related air pollution with cognitive development in children. J Epidemiol Community Health. 2010 Mar;64(3):223-8.

63. Ribas-Fito N, Julvez J, Torrent M, Grimalt JO, Sunyer J. Beneficial effects of breastfeeding on cognition regardless of DDT concentrations at birth. 
AmJEpidemiol. 2007 Nov 15;166(1476-6256 (Electronic)):1198-1202.

64. Guxens M, Mendez MA, Molto-Puigmarti C, et al. Breastfeeding, long-chain polyunsaturated Fatty acids in colostrum, and infant mental development.

Pediatrics. 2011 Oct;128(1098-4275 (Electronic)):e880-e889.

65. Julvez J, Guxens M, Carsin A-E, et al. A cohort study on full breastfeeding and child neuropsychological development: the role of maternal social, psychological, and nutritional factors. Dev Med Child Neurol. 2014 Feb;56(2):148-56.

66. Morales E, Bustamante M, Gonzalez JR, et al. Genetic variants of the FADS gene cluster and ELOVL gene family, colostrums LC-PUFA levels, breastfeeding, and child cognition. PLoS One. 2011 Jan;6(2):e17181.

67. Pérez-Lobato R, Mustieles V, Calvente I, et al. Exposure to Bisphenol A and behavior in school-age children. Neurotoxicology. 2015 Dec 4;53:12-19.

68. Calvente I, Pérez-Lobato R, Núñez M-I, et al. Does exposure to environmental radiofrequency electromagnetic fields cause cognitive and behavioral effects in 10-year-old boys? Bioelectromagnetics. 2016 Jan;37(1):25-36.

69. Forns J, Vegas O, Julvez J, et al. Association between child cortisol levels in saliva and neuropsychological development during the second year of life. Stress Health. 2014 Apr;30(2):142-8.

70. Alvarez-Pedrerol M, Ribas-Fitó N, Torrent M, Julvez J, Ferrer C, Sunyer J. TSH concentration within the normal range is associated with cognitive function and ADHD symptoms in healthy preschoolers. Clin Endocrinol (Oxf). 2007 Jun;66(6):890-8.

71. Pérez-Lobato R, Ramos R, Arrebola JP, et al. Thyroid status and its association with cognitive functioning in healthy boys at 10 years of age. Eur $J$ Endocrinol. 2015 Feb;172(2):129-39.

72. Julvez J, Torrent M, Guxens M, Antó JM, Guerra S, Sunyer J. Neuropsychologic status at the age 4 years and atopy in a population-based birth cohort. Allergy. 2009 Sep;64(9):1279-85.

73. Sunyer J, Basagana X, Gonzalez JR, et al. Early life environment, neurodevelopment and the interrelation with atopy. Env Res. 2010 Oct;110(1096-953):733-738.

74. Guxens M, Mendez MA, Julvez J, et al. Cognitive function and overweight in preschool children. Am J Epidemiol. 2009 Aug 15;170(4):438-46.

75. Cohen AJ, Ross Anderson H, Ostro B, et al. The global burden of disease due to outdoor air pollution. $J$ Toxicol Environ Health A [Internet]. Jan [cited 2015 Jan 23];68(13-14):1301-7. Available from: http://www.ncbi.nlm.nih.gov/pubmed/16024504

76. Stahlhut RW, Welshons W V, Swan SH. Bisphenol A data in NHANES suggest longer than expected half-life, substantial nonfood exposure, or both. Environ Health Perspect. 2009 May;117(5):784-9.

77. Hauser R, Calafat AM. Phthalates and human health. Occup Environ Med. 2005 Nov;62(11):806-18.

78. Egeghy PP, Cohen Hubal EA, Tulve NS, et al. Review of pesticide urinary biomarker measurements from selected US EPA children's observational exposure studies. Int J Environ Res Public Health. 2011 May;8(5):1727-54.

79. Grandjean P. Only One Chance: How Environmental Pollution Impairs Brain Development -- and How to Protect the Brains of the Next Generation. 1st Editio. Environmental ethics and science policy series, editor. Oxford University Press; 2013. 
80. Vrijheid M, Slama R, Robinson O, et al. The human early-life exposome (HELIX): project rationale and design. Environ Health Perspect. 2014 Jun;122(6):535-44.

81. Wild CP. The exposome: from concept to utility. IntJEpidemiol. International Agency for Research on Cancer, 150 cours Albert Thomas, 69008 Lyon, France. director@iarc.fr; 2012 Feb;41(1464-3685 (Electronic)):24-32. 
Table 1. List of neuropsychological tests conducted in the INMA Project across regions.

\begin{tabular}{|c|c|c|c|c|c|c|c|c|c|}
\hline Age & Domains & 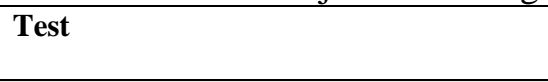 & $\begin{array}{l}\text { Ribera } \\
\text { d'Ebre }\end{array}$ & Menorca & Granada & Asturias & Valencia & Gipuzkoa & Sabadell \\
\hline \multicolumn{10}{|c|}{$1 \mathrm{y}-2 \mathrm{y}$} \\
\hline & \multirow{2}{*}{ Cognitive and psychomotor development } & BSID-I & $\mathrm{X}$ & --- & --- & $\mathrm{X}$ & $\mathrm{X}$ & $\mathrm{X}$ & $\mathrm{X}$ \\
\hline & & GSID & $\mathrm{X}$ & --- & --- & --- & --- & --- & --- \\
\hline \multicolumn{10}{|c|}{$4 y-5 y$} \\
\hline & Cognitive and psychomotor development & MCSA & $\mathrm{X}$ & $\mathrm{X}$ & $\mathrm{X}$ & $\mathrm{X}$ & $\mathrm{X}$ & $\mathrm{X}$ & $\mathrm{X}$ \\
\hline & Attentional function & $\mathrm{K}-\mathrm{CPT}$ & --- & --- & --- & $\mathrm{X}$ & $\mathrm{X}$ & $\mathrm{X}$ & $\mathrm{X}$ \\
\hline & ADHD symptoms & ADHD - DSM IV & $\mathrm{X}$ & $\mathrm{X}$ & $\mathrm{X}$ & $\mathrm{X}$ & $\mathrm{X}$ & $\mathrm{X}$ & $\mathrm{X}$ \\
\hline & Behavioral problems & SDQ & --- & --- & --- & --- & --- & $\mathrm{X}$ & --- \\
\hline & Social competence & CPSCS & $\mathrm{X}$ & $\mathrm{X}$ & $\mathrm{X}$ & $\mathrm{X}$ & $\mathrm{X}$ & $\mathrm{X}$ & $\mathrm{X}$ \\
\hline & \multirow[t]{2}{*}{ Autistic traits } & CAST & --- & --- & --- & $\mathrm{X}$ & $\mathrm{X}$ & $\mathrm{X}$ & $\mathrm{X}$ \\
\hline & & Batelle & --- & --- & --- & $\mathrm{X}$ & --- & --- & $\mathrm{X}$ \\
\hline \multicolumn{10}{|c|}{$7 y-8 y$} \\
\hline & Working memory & N-back test & --- & --- & --- & $\mathrm{X}$ & $\mathrm{X}$ & --- & $\mathrm{X}$ \\
\hline & Processing speed & Finger tapping test & --- & --- & --- & $\mathrm{X}$ & $\mathrm{X}$ & --- & $\mathrm{X}$ \\
\hline & Attentional function & ANT & --- & --- & --- & $\mathrm{X}$ & $\mathrm{X}$ & --- & $\mathrm{X}$ \\
\hline & Behavioral problems & SDQ & --- & -- & --- & $\mathrm{X}$ & $\mathrm{X}$ & $\mathrm{X}$ & $\mathrm{X}$ \\
\hline & & CSRS & --- & --- & --- & $\mathrm{X}$ & $\mathrm{X}$ & --- & $\mathrm{X}$ \\
\hline \multicolumn{10}{|c|}{$8 y-10 y$} \\
\hline & Cognitive development & K-BIT & --- & --- & $\mathrm{X}$ & --- & --- & --- & --- \\
\hline & \multirow[t]{2}{*}{ Working memory } & N-back test & --- & --- & --- & --- & --- & $\mathrm{X}$ & $\mathrm{X}$ \\
\hline & & WISC-IV subtest (letter-number seq.) & --- & -- & $\mathrm{X}$ & --- & $\mathrm{X}$ & --- & --- \\
\hline & Mental flexibility & TMT - part B & --- & -- & $\mathrm{X}$ & --- & --- & $\mathrm{X}$ & $\mathrm{X}$ \\
\hline & \multirow[t]{2}{*}{ Processing speed } & WISC-IV subtest (coding, symbol search) & --- & --- & $\mathrm{X}$ & --- & $\mathrm{X}$ & $\mathrm{X}$ & $\mathrm{X}$ \\
\hline & & Finger tapping test & --- & --- & --- & --- & --- & $\mathrm{X}$ & $\mathrm{X}$ \\
\hline & Visuo-motor coordination & TMT - part A & --- & --- & $\mathrm{X}$ & --- & -- & $\mathrm{X}$ & $\mathrm{X}$ \\
\hline & Verbal development & BEST & --- & --- & --- & --- & -- & $\mathrm{X}$ & --- \\
\hline
\end{tabular}




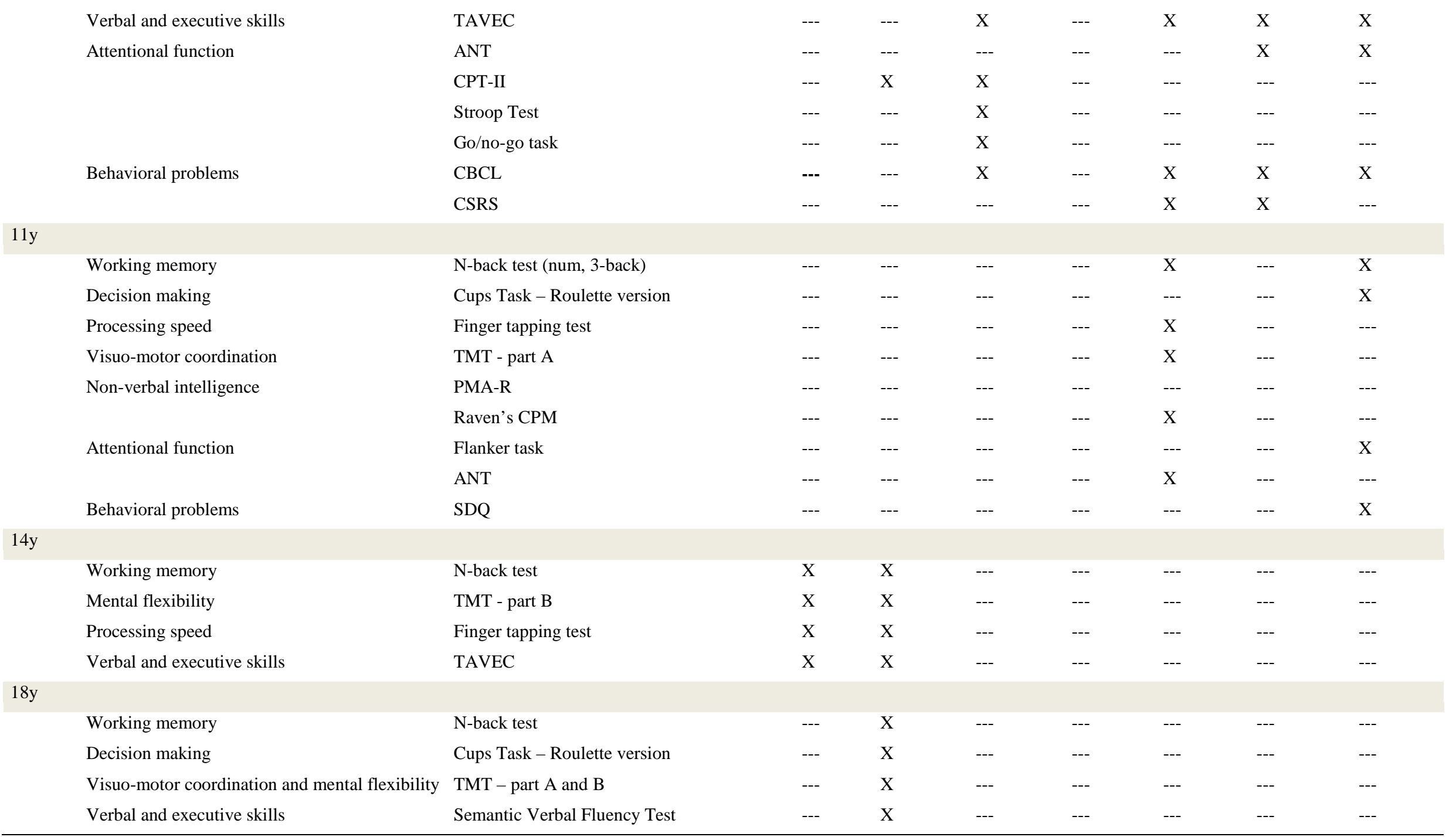

Bayley Scales of Infant Development 1st edition (BSID-I) 
Griffiths Scales of Infant Development (GSID)

McCarthy Scales of Children's Abilities (MSCA)

Conners’ Kiddie Continuous Performance Test (K-CPT)

Attention-Deficit Hyperactivity Disorder Criteria of the Diagnostic and Statistical Manual of Mental Disorders 4th Edition (ADHD-DSM-IV)

California Preschool Social Competence Scale (CPSCS)

Childhood Asperger Syndrome Test (CAST)

Strengths and Difficulties Questionnaire (SDQ)

Conners' Parent Rating Scales (CSRS)

Trail Making Test (TMT)

Child behavior checklist (CBCL)

Attention Network Test (ANT)

Wechsler Intelligence Scale for Children, $4^{\text {th }}$ Edition (WISC-IV)

Kaufman Brief Intelligence Test (K-BIT)

Basque, English, Spanish Test (BEST) - based on MINT and Colorized Snodgrass and Vanderwart Pictures

Semantic Verbal Fluency Test (TAVEC)

Continuous Performance Test (CPT)

Primary Mental Abilities Test- Reasoning (PMA-R)

Raven's Coloured Progressive Matrices (Raven’s CPM) 
Table 2. Studies and associations observed by each study between prenatal determinants and cognitive and psychomotor development and behavioural outcomes between 1 and 7 years.

\begin{tabular}{|c|c|c|c|c|c|c|c|}
\hline & \multicolumn{2}{|c|}{$\begin{array}{c}\text { Cognitive and psychomotor } \\
\text { development }\end{array}$} & \multirow{2}{*}{\begin{tabular}{|l|}
$\begin{array}{c}\text { Poor social } \\
\text { competence }\end{array}$ \\
4-5 years \\
CSPCS
\end{tabular}} & \multirow{2}{*}{$\begin{array}{l}\begin{array}{l}\text { ADHD } \\
\text { symptoms }\end{array} \\
\text { 4-5 years } \\
\text { ADHD-DSM IV }\end{array}$} & \multirow{2}{*}{$\begin{array}{l}\begin{array}{l}\text { Behavioural } \\
\text { problems }\end{array} \\
7 \text { years } \\
\text { SDQ }\end{array}$} & \multirow{2}{*}{\begin{tabular}{|l|}
$\begin{array}{l}\text { Conduct } \\
\text { problems }\end{array}$ \\
$4-5$ years \\
CAST
\end{tabular}} & \multirow{2}{*}{\begin{tabular}{|l|}
$\begin{array}{l}\text { Autism- } \\
\text { spectrum } \\
\text { traits }\end{array}$ \\
7 years \\
CSRS
\end{tabular}} \\
\hline & $\begin{array}{l}1 \text { year } \\
\text { BSID/GSID }\end{array}$ & $\begin{array}{l}\text { 4-5 years } \\
\text { MCSA }\end{array}$ & & & & & \\
\hline \multicolumn{8}{|l|}{ POPs } \\
\hline DDT/DDE & $\downarrow X$ & $\downarrow$ & & & & & \\
\hline PCBs & $\mathrm{X} \downarrow$ & $\downarrow$ & & & & & \\
\hline HCB & $X X$ & & $\uparrow$ & $\uparrow$ & & & \\
\hline Mirex & & $\downarrow$ & & & & & \\
\hline PBDEs & $\downarrow$ & $\mathrm{X}$ & $\mathrm{X}$ & $\mathrm{X}$ & & & \\
\hline \multicolumn{8}{|l|}{ Metals } \\
\hline Mercury (Hg) & $\mathrm{X}$ & & & & & & \\
\hline Others $^{\mathrm{a}}$ & & $\mathrm{X}$ & & $\mathrm{X}$ & & & \\
\hline \multicolumn{8}{|l|}{ Outdoor air pollution } \\
\hline $\mathrm{NO}_{2}$ & $X \downarrow$ & $\downarrow^{\mathrm{b}}$ & & & & $X^{c}$ & \\
\hline $\mathrm{NO}_{\mathrm{x}}$ & $\mathrm{XX}$ & $\mathrm{X}^{\mathrm{b}}$ & & & & $X^{c}$ & \\
\hline Benzene & $\mathrm{X}$ & & & & & & \\
\hline $\mathrm{PM}_{2.5}$ & $\downarrow$ & $X^{b}$ & & & & $\mathrm{X}^{\mathrm{c}}$ & \\
\hline $\mathrm{PM}_{10}$ & & $\mathrm{X}^{\mathrm{b}}$ & & & & $X^{\mathrm{c}}$ & \\
\hline $\mathrm{PM}_{\text {coarse }}$ & & $\mathrm{X}^{\mathrm{b}}$ & & & & $\mathrm{X}^{\mathrm{c}}$ & \\
\hline \multicolumn{8}{|l|}{$\begin{array}{l}\text { Residential indoor air } \\
\text { pollution }\end{array}$} \\
\hline Use of gas appliances at home & $\downarrow$ & $\downarrow$ & & $\uparrow$ & & & \\
\hline $\mathrm{NO}_{2}$ & & $\downarrow$ & & $\uparrow$ & & & \\
\hline \multicolumn{8}{|l|}{ Maternal smoking } \\
\hline & & $\downarrow$ & & & & & \\
\hline \multicolumn{8}{|l|}{ Maternal fish intake } \\
\hline & $\uparrow$ & $X^{\mathrm{d}} \uparrow$ & & & & $\downarrow$ & \\
\hline \multicolumn{8}{|l|}{$\begin{array}{l}\text { Maternal dietetic supplements } \\
\text { intake }\end{array}$} \\
\hline $\begin{array}{l}\text { Folic acid } \\
\text { Iodine }\end{array}$ & $\begin{array}{l}\downarrow^{e} \\
\downarrow x\end{array}$ & $\uparrow$ & $\downarrow$ & $\downarrow$ & & & \\
\hline \multicolumn{8}{|l|}{ Maternal determinants } \\
\hline TSH concentrations & & $\downarrow$ & & & & & \\
\hline Low free thyroxine levels & $\downarrow$ & & & & & & \\
\hline Maternal intelligence (IQ) & $X^{f}$ & & & & & & \\
\hline
\end{tabular}


Obesity

$\downarrow$

\begin{tabular}{|c|c|c|c|c|c|c|}
\hline \multicolumn{7}{|l|}{ Vitamin D } \\
\hline & $\uparrow$ & & & $\downarrow$ & & \\
\hline \multicolumn{7}{|l|}{ Bisphenol A (BPA) } \\
\hline & $\downarrow$ & $\mathrm{X}$ & & $\uparrow$ & $\mathrm{X}$ & $\mathrm{X}$ \\
\hline \multicolumn{7}{|l|}{ Phthalates } \\
\hline$\Sigma_{4} \mathrm{DEHPs}$ & $\mathrm{X}$ & $\mathrm{X}$ & $\downarrow$ & $\downarrow$ & $\mathrm{X}$ & $\downarrow$ \\
\hline MBzP & $\mathrm{X}$ & $\downarrow$ & $\mathrm{X}$ & $\mathrm{X}$ & $\mathrm{X}$ & $\mathrm{X}$ \\
\hline MEP & $\mathrm{X}$ & $\mathrm{X}$ & $\mathrm{X}$ & $\downarrow$ & $\mathrm{X}$ & $\mathrm{X}$ \\
\hline MiBP & $\mathrm{X}$ & $\mathrm{X}$ & $\mathrm{X}$ & $\mathrm{X}$ & $\mathrm{X}$ & $\mathrm{X}$ \\
\hline MnBP & $\mathrm{X}$ & $\mathrm{X}$ & $\mathrm{X}$ & $\mathrm{X}$ & $\mathrm{X}$ & $\mathrm{X}$ \\
\hline \multicolumn{7}{|l|}{ Other determinants } \\
\hline $\begin{array}{l}\text { Pre- and perinatal head } \\
\text { circumference }\end{array}$ & $\mathrm{X}$ & & & & & \\
\hline TEXB-alpha & $X^{g}$ & $\mathrm{X}$ & & & & \\
\hline $\begin{array}{l}\text { Use of non-persistent } \\
\text { pesticides }\end{array}$ & $\downarrow$ & & & & & \\
\hline Pet ownership & & $\mathrm{X}$ & $\mathrm{X}$ & & & \\
\hline Cell phone use & $\mathrm{X}$ & & & & & \\
\hline
\end{tabular}

Attention-Deficit Hyperactivity Disorder Criteria of the Diagnostic and Statistical Manual of Mental Disorders 4th Edition (ADHD-DSM-IV); Bayley Scales of Infant Development (BSID);

California Preschool Social Competence Scale (CPSCS); Childhood Asperger Syndrome Test (CAST); Conners' Parent Rating Scales (CSRS); Griffiths Scales of Infant Development (GSID);

McCarthy Scales of Children’s Abilities (MCSA); Strengths and Difficulties Questionnaire (SDQ); Total Effective Xenoestrogen Burden

$\uparrow=$ increased risk/coefficient

$\downarrow=$ decreased risk/coefficient

$\mathrm{X}=$ no associations found

Empty space indicates no studies available

${ }^{a}$ Cobalt, cupper, arsenic, cadmium, antimony and lead

${ }^{\mathrm{b}}$ This study was conducted combining data of children from 1 to 6 years of age.

${ }^{\mathrm{c}}$ This study was conducted combining data of children from 4 to 10 years of age.

${ }^{\mathrm{d}}$ Associations observed only among children breastfeeding for $<6$ months.

${ }^{\text {e}}$ Association observed in mothers with intakes of folic acid of $>5000 \mu \mathrm{g} /$ day compared to mothers with intakes of the recommended dose (400-1000 $\left.\mu \mathrm{g} / \mathrm{day}\right)$.

${ }^{\mathrm{f}}$ Associations only observed in children of more disadvantaged occupational social classes.

${ }^{\mathrm{g}}$ Only psychomotor effects observed in boys. 
Table 3. Studies and associations observed by each study between postnatal determinants and cognitive and psychomotor development and behavioural outcomes between 1 and 5 years ${ }^{\mathrm{a}}$.

\begin{tabular}{|c|c|c|c|c|}
\hline & \multicolumn{2}{|c|}{ Cognitive and psychomotor development } & \multirow{3}{*}{$\begin{array}{l}\text { Poor social competence } \\
4-5 \text { years } \\
\text { CSPCS }\end{array}$} & \multirow{3}{*}{$\begin{array}{l}\text { ADHD symptoms } \\
\text { 4-5 years } \\
\text { ADHD-DSM IV }\end{array}$} \\
\hline & & 4-5 years & & \\
\hline \multirow{2}{*}{\multicolumn{5}{|c|}{ POPs }} \\
\hline & & & & \\
\hline DDT/DDE & $\mathrm{X}$ & & & \\
\hline PCBs & $\mathrm{X}$ & $\mathrm{X}$ & & \\
\hline HCB & $\mathrm{X}$ & & & \\
\hline \multicolumn{5}{|l|}{ Mirex } \\
\hline PBDEs & & $\mathrm{X}$ & $\uparrow$ & $\uparrow$ \\
\hline \multicolumn{5}{|l|}{ Metals } \\
\hline Mercury (Hg) & & $\downarrow$ & & \\
\hline \multicolumn{5}{|l|}{ Outdoor air pollution } \\
\hline $\mathrm{NO}_{2}$ & & $\mathrm{X}$ & & \\
\hline \multicolumn{5}{|l|}{ Maternal smoking } \\
\hline & & $\mathrm{X}$ & & \\
\hline \multicolumn{5}{|l|}{ Breastfeeding } \\
\hline Breastfeeding $>4$ to 6 months & $\uparrow \uparrow$ & $\uparrow \uparrow$ & $\downarrow$ & $\downarrow$ \\
\hline LC-PUFA & $\uparrow$ & & & \\
\hline Omega n3 fatty acid & & $\mathrm{X}$ & & \\
\hline \multicolumn{5}{|l|}{ Other determinants } \\
\hline Use of non-persistent pesticides & $\mathrm{X}$ & & & \\
\hline Persistent home dampness & & $\downarrow$ & $\downarrow$ & \\
\hline Pet ownership & & $\mathrm{X}$ & $\mathrm{X}$ & \\
\hline Farm animal contact & & $\uparrow$ & $\mathrm{X}$ & \\
\hline Measured microbial compounds & & $\mathrm{X}$ & $\mathrm{X}$ & \\
\hline Cortisol & $\uparrow$ & & & \\
\hline
\end{tabular}

Attention-Deficit Hyperactivity Disorder Criteria of the Diagnostic and Statistical Manual of Mental Disorders 4th Edition (ADHD-DSM-IV); Bayley Scales of Infant Development (BSID); California Preschool Social Competence Scale (CPSCS); Childhood Asperger Syndrome Test (CAST); Child Behaviour Checklist (CBCL/6-18); Conners' Parent Rating Scales (CSRS); Griffiths Scales of Infant Development (GSID); Long-chain polyunsaturated fatty acid (LC-PUFA); McCarthy Scales of Children's Abilities (MCSA); Strengths and Difficulties Questionnaire (SDQ)

$\uparrow=$ increased risk/coefficient

$\downarrow=$ decreased risk/coefficient

$\mathrm{X}=$ no associations found

Empty space indicates no studies available

${ }^{a}$ No studies available neuropsychological evaluating outcomes at the age of 7 years, only two studies evaluated neuropsychological outcomes at the age of 9-11 years (see text). 